\title{
Association of Temporomandibular Joint Disorders with Habitual Sleeping Body Posture and Nasal Septal Deviation
}

\author{
'Esin Yalçınkaya \\ 1 Medisun Hospital, Otolaryngology Department, Ankara, Turkey ORCID ID: 0000-0002-3980-3850
}

\begin{abstract}
Objective: The present study aimed to evaluate the long term results of our previous study. In the previous study, we found that temporomandibular joint disorders(TMJDs) are related to habitual prone sleeping position and nasal septal deviation.

Methods: Of 200 participants 104 patients were diagnosed as TMJD. After five years we evaluated 101 of 104 patients by means of TMJD sympthoms. By these years 27 of 65 patients with nasal septal deviation had gone to septoplasty.
\end{abstract}

Results: 24 of 27 patients with nasal septal deviation were improved $(88.8 \%)$. Additionally, 27 of 50 patients who changed their habitual sleeping position also improved (54\%).

Conclusion: This study showed that correcting nasal septal deviation and habitual prone sleeping position improves temporomandibular joint disorder sympthoms.

Key words: Temporomandibular joint disorder, sleep position, nasal septal deviation

\section{Introduction}

Temporomandibular joint disorders are musculoskeletal disorders affecting the jaw joint and chewing muscules. Frequent symptoms are pain in the orofacial region, limited jaw movement and sounds originating in the joint. Aetiology of TMJDs can be psychological, neuromuscular and anatomical (1).

The turbinates and nasal mucosal vessels regulate nasal airflow, and heat, humidty, cleaning of breath. The mucosal blood vessels are also important for nasal resistance (2). Nasal cycle is a physiologic intermittent change of nasal airway resistance. The period of nasal cycle varies between 2 and 6 hours. During one cycle, one side (left or right) of nasal cavity mucosa congests and the other side decongests.
And in the following cycle, opposite side congests, and previously congested side decongests (3).

Left or right lateral body posture while sleeping eliminates nasal cycle. For example, while sleeping on left side, by the effect of gravity, the left (inferior) nasal passage blood vessels congest and the nasal passage narrows, and the opposite side decongests $(2,3)$. If an individual has a nasal septal deviation, he or she will be more confortable when sleeping on septal deviation side. For example, if there is a nasal septal deviation on left side, sleeping on the left will give the opportunity to breath on right side cause by the gravity nasal blood will also be on the left side, otherwise the both nasal passege would be narrowed (3).

There are many studies evaluating the relationship be-
Correspondence: Esin Yalçınkaya,

Medisun Hospital, Otolaryngology Department, Ankara, Turkey

e-mail: esinkbbesin@gmail.com

Received: 4.03.2019; Accepted: 17.03.2019
Online available at: www.entupdates.org

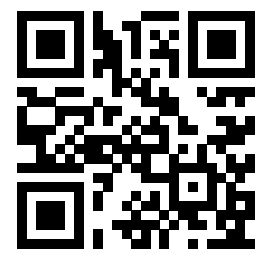


tween head and body posture with TMJDs $(4,5)$. However, we can reach limited information about the ralationship between habitual sleeping body posture and TMJDs. Hibi and Ueda investigated that habitual body posture was associated with anterior disc displacement. 87 samples were questioned about their habitual body posture and magnetic resonance imaging were used for the evalution of temporomandibular joint (6).

In our previous study we eveluated the relationships between TMJD; habitual sleeping body posture (HSBP) and nasal septal deviation (NSD). And found that, one having an unilateral obstructive nasal septal deviation in addition to a habit of sleeping in prone position has high risk of TMJD. And in this study, we presented the five years followings of our participant patients.

\section{Materials and Methods}

A controlled clinical trial was carried out. The study protocol was approved by ethics commity and an informed consent was obtained from all participants.

Of 200 participants of the previous study, 104 patients were diagnosed to have TMJD. We evaluated the follow up of these 101 patients in our study. 3 patients could not be followed for passed 5 years. 62 females and 39 males were enrolled to study. All patients were questioned about their habitual sleeping body posture, also confirmed by their family members and examined with nasal endoscopy. Patients with habitual chewing side, bruxism, dentofacial anomalies, incomplete dentition, orofacial trauma history, orthopedic or orthodontic treatment of the jaws were excluded in the previous study.

Table 1: TMJD (+) patients divided in groups considering NSD and HSBP

\begin{tabular}{lll}
\hline Groups & & Number of TMJD (+) patients \\
\hline I & NSD (-), HPSBP (-) & 8 \\
II & NSD (+), HPSBP (-) & 24 \\
III & NSD (-), HPSBP (+) & 28 \\
IV & NSD (+), HPSBP (+) & 41 \\
\hline
\end{tabular}

TMJD: Temporomandibular joint syndrome, NSD: Nasal septal deviation, HSBP: Habitual prone sleeping body posture

In these 5 years, 27 of 65 patients had an septoplasty operation. We recommend all patients TMJDs advices as chewing habitually both side not one side, not biting tough nutrients, and protecting the jaw joints in cold weathers. And also adviced, all TMJD patients with habit of sleeping prone position, to sleep backpack or both sides alternately. After 5 years follow up, all participants were clinically examined according to Research Diagnostic Criteria for TMD (RDC/TMD), and were classified as having muscle or joint disorders (8). Case classification of TMD based on two criteria: (1) C5 days of pain in masticatory structures, (2) examiner findings of arthralgia (pain response to jaw movements or digital palpation of one or both temporomandibular joints) and/or myalgia (pain response to digital palpation of $\mathrm{C} 3$ of 8 muscles based on bilateral assessment of temporalis, masseter, lateral pterygoid, and submandibular muscles).

\section{Results}

101 patients with a mean age of 42.65 were evaluated. Females were $62.6 \%$, and males were $37.4 \%$ of participants. 24 of the 27 patients who went septoplasty improved, that result shows that having septoplasty and training of advices for TMJD has $88.8 \%$ success (Table 2). And After exclusion of patients who went septoplasty, we can see that 27 of 50 patients improved. And this result shows that changing habits of sleeping position with training TMJD advices has a success of $54 \%$.

Table 2: 5 years follow uo of NSD(+) , TMJD(+) patients

\begin{tabular}{lllll}
$\begin{array}{l}\text { NSD(+) } \\
n=65\end{array}$ & \multicolumn{2}{l}{ septoplasty applied } & \multicolumn{2}{l}{ Septoplasty not applied } \\
& $\begin{array}{l}5 \text { years } \\
\text { ago }\end{array}$ & $\begin{array}{l}5 \text { years } \\
\text { after }\end{array}$ & $\begin{array}{l}5 \text { years } \\
\text { ago }\end{array}$ & 5 years after \\
\hline $\begin{array}{l}\text { HPSBP(+)in } \\
n=24\end{array}$ & $n=8$ & $\begin{array}{l}n=1 \\
(12.5 \%)\end{array}$ & $n=16$ & $n=10(62.5 \%)$ \\
$\begin{array}{l}\text { HPSBP(-) } \\
n=41\end{array}$ & $n=19$ & $\begin{array}{l}n=2 \\
(10.5 \%)\end{array}$ & $n=22$ & $n=14(63.6 \%)$ \\
\hline
\end{tabular}

NSD: Nasal septal deviation, HSBP: Habitual prone sleeping body posture TMJD: Temporomandibular joint dysfunction

Table 3: 5 years follow up of HSBP(+), TMJD(+) patients after exclusion of patients applied septoplasty

\begin{tabular}{lll}
$\begin{array}{l}\text { HPSBP(+), TMJD(+) } \\
\mathbf{n}=50\end{array}$ & $\mathbf{5}$ years before & $\mathbf{5}$ years after \\
\hline $\mathrm{NSD}(+)$ & $\mathrm{n}=22$ & $13(59.0 \%)$ \\
$\mathrm{NSD}(-)$ & $\mathrm{n}=28$ & $10(35.7 \%)$ \\
\hline
\end{tabular}

HSBP: Habitual prone sleeping body posture, NSD: Nasal septal deviation, TMJD: Temporomandibular joint dysfunction 


\section{Discussion}

People having nasal septum deviation are known to sleep laterally at the deviation side and their mouth will be open while sleeping because of the nasal resistance (3). In our previous study our hypothesis was that if people with nasal septal deviation had also a habit of sleeping in prone position, sleeping all night at lateral side with open mouth might cause anterior disc displacement. Results of our previous study showed that, TMJD percentage of participants were in the groups; (NSD(-), HPSBP(-)); (NSD(-), HPS$\mathrm{BP}(-))$; (NSD(-), HPSBP(-)); (NSD(-), HPSBP(-)) were $\% 4 ; \% 12 ; \% 14 ; \% 22$, respectively (7). In the presented study, we evaluated five years follow up of the participants of previous study who had the diagnosis of TMJD. And determined that having septoplasty and training of advices for TMJD has $88.8 \%$ success (Table 2), and changing habits of sleeping position with training TMJD advices has $54 \%$ success for improvement of TMJD.

Aetiology, diagnosis and treatment of temporomandibular disorders are still controversial. Habit of unilateral chewing, missing or deficient teeth (especially the posterior teeth), trauma, neuromuscular disorders, bruksizm, orthognatic diseases, craniocervical postural problems, inflammatory arthritis, even the smart phone usage were blamed up to date $(4,9,10)$. The posture of the head and the body is thought to play an important role in the aetiology of temporomandibular disorders because chronically altered craniocervical posture can lead to mandibular postural changes (4).

Hibi and Ueda reported that the anterior disc displacement is associated with the habitual lateral sleeping position. They suggested that depending on gravity mandib- ular rest position may change. This situation leads to the deviation of the ipsilateral condyle posterolaterally and the contralateral one anteromedially (6). Superior positioning of the ipsilateral condyle makes compression to the posterior band of the disc or the retrodiscal tissue and makes this tissue thin which limits the condyle motions (6). Austin also determined a relationship between prone or lateral habitual sleeping positions predispose TMJD (11).

Patients with nasal septal deviation are known to sleep as their mouth open to breath easy because of narrowed nasal passages. Also individuals with obstructive nasal septal deviation tends to sleep laterally, for the reason that by the gravity blood in nasal mucosal vessels accumulated at the sleeping side $(2,3)$. And, if they sleep at their deviation side, this will facilitate breathing by the opposite nasal cavity.

We hypothesized that if one has a habit of sleeping in prone position in addition to nasal septal deviation, he or she will sleep all night prone and laterally on one side with open mouth and this would cause anterior disc displacement. And, in our previous study we found that sleeping laterally and especially sleeping in prone position causes TMJD in patients with nasal septal deviation. And, our presented study showed that 7 of 8 patients $(87.5 \%)$, who went septoplasty, changed habitual sleeping posture and obeyed temporomandibular disorder advices improved after 5 years follow up (Table 2).

To conclude, nasal septal deviation, habitual sleeping positions of laterally and prone predisposes TMJD. Correcting these situations in addition to temporomandibular joint preventation advices will improve the sympthoms. 


\section{References}

1. Pereira LJ, Gaviir MB, Bonjardim LR, et al. Muscle thickness, bite force, and craniofacial dimensions in adolescents with signs and symptoms of temporomandibular dysfunction. Eur J Orthod 2007; 29:72-8.

2. Beule AG. Physiology and pathophysiology of respiratory mucosa of the nose and paranasal sinuses. GMS Curr Top Otorhinolaryngol Head Neck Surg 2010; 9:23-25.

3. Ozcan M. Nasal anatomy and physiology. In: Koc C (ed) Ear nose thorat diseases, head and neck surgery, 2nd edn. Turkey, Ankara, 2013, pp 391396.

4. Cortese S, Mondello A, Galarza R, et al. Postural alternations as a risk factor for temporomandibular disorders. Acta Odontol Latinoam, 2017, 30; 57-60.

5. Chaves PJ, Oliveira FEM, Moreira LC, et al. Incidence of Postural Changes and Temporomandibular Disorders in Students. Acta Ortop Bras, 2017, 25; 162-4.
6. Hibi H, Ueda M (2006) Body posture during sleep and disc displacement in the temporomandibular joint: a pilot study. J Oral Rehabil 32:85-89.

7. Yalcinkaya E, Cingi C, Muluk NB. Are temporomandibular disorders associated with habitual sleepind body posture or nasal septal deviation?

8. Chen H, Slade G, Lim PF, et al. Relationship between temporomandibular disorders, widespread palpation tenderness and multiple pain conditions: a case-control study. J Pain 2012, 13;1016-1027

9. Faulin EF, Guedes CG, Feltrin PP. Association with temporomandibular disorders and abnormal head postures. Braz Oral Res 2015, 29;1-6.

10. Kee IK, Byun JS, Jung JK, et al. The presence of altered craniocervical posture and mobility in smartphone-addicted tenagers with temporomandibular disorders. J Phys Ther Sci 2016, 28; 339-346.

11. Austin DG (1997) Special considerations in orofacial pain and headache. Dental Clin N Am 41:325

This is an open access article distributed under the terms of the Creative Commons Attribution-NonCommercial-NoDerivs 3.0 Unported (CC BY- NC-ND3.0) Licence (http://creativecommons.org/licenses/by-nc-nd/3.0/) which permits unrestricted noncommercial use, distribution, and reproduc- tion in any medium, provided the original work is properly cited.

Please cite this article as: Yalçınkaya E., Association of Temporomandibular Joint Disorders with Habitual Sleeping Body Posture and Nasal Septal Deviation. ENT Updates 2019;9(1): 64-67 